\title{
A STUDY OF MOTIVATIONAL ASPECTS INITIATING VOLUNTEERISM IN DISASTER MANAGEMENT IN GERMANY
}

\author{
P. HOLWITT, S. STROHSCHNEIDER, R. ZINKE, S. KAISER, I. KRANERT, A. LINKE \& M. MÄHLER
}

Department of Intercultural Studies and Business Communications, Friedrich-Schiller University, Jena, Germany.

\begin{abstract}
Volunteer work is an important aspect that influences a society's ability to cope with different kinds of security threats and disasters. However, the motivational and social sources that drive civil engagement in the field of disaster management are not understood very well. If societies want to preserve or increase their resilience and thus reduce their vulnerability to disasters, volunteerism is an important topic to look into. In order to foster voluntary engagement in disaster management, it is essential to both understand the motivational sources that drive volunteers and establish appropriate conditions for future voluntary engagement. In this article, motivations of volunteers in three regions of Germany are analysed using a theoretical model that builds on the works by psychologists Dörner and Bischof. The model considers volunteerism as a way of catering to three basic needs of human beings: the need for affiliation, the need for certainty and the need for control. This model is applied to data gathered from unstructured and semi-structured interviews with volunteers and professionals working in the field of disaster management in Germany.

Keywords: disaster management, Germany, motives, training, volunteerism.
\end{abstract}

\section{INTRODUCTION}

In recent years, the concept of volunteer work is undergoing fundamental changes: long-term commitment to a particular organization or team is decreasing and, at the same time, more flexible forms of voluntary engagement are emerging. These new forms of volunteerism often respond to single urgent crises and quickly disperse again. New modes of communication and coordination foster this incident-related volunteerism. Furthermore, volunteer work attracts only particular segments of society, while others are under-represented, particularly elderly people and migrants. These transformations of volunteerism and shortcomings of traditional modes of managing volunteers are challenges to organizations that operate in the field of disaster management and are hence asking for a rethinking of strategies.

In this article, we present a theoretical model that builds on psychological theory and can be used to understand the motivational sources of volunteers who work in the field of disaster management. We apply this model to study the motivational sources of volunteers who work in the field of disaster management in three regions of Germany. The model is intended to help understand the different motivations of volunteers and to account for their various reasons to take up voluntary work in the field of disaster management.

The study presented here was carried out within the collaborative Indo-German research project 'INitiate VOLunteerism to counter VulnErability' [1]. The focus of the German study was on sources and motivations of voluntary engagement in disaster management in selected German regions contributing to an increase of societal resilience. The project aims at generating knowledge about why and in which ways people engage in voluntary work in the field of disaster management and to improve ways of integrating volunteers into established structures of professional disaster management organ,izations based on these findings. It is yet an ongoing research project and the results presented in this article are still at a preliminary stage. 
The article is structured in the following way: it starts with a short review of the state of the art regarding works from various disciplinary backgrounds that engage with motivational sources of volunteerism. In accordance with the approach presented in this article, a special focus lies on psychological theories about volunteerism. After this brief overview, the theoretical model applied in the INVOLVE-project is presented. The next section explains the wider context of our data collection and the methods used. In the final section, the theoretical model is applied to data gathered in the context of the research project. The conclusion summarizes the preliminary results of the project and presents the implication of interventions in existing trainings and work routines of organizations working in the field of disaster management.

\section{VOLUNTEERISM AND MOTIVATION}

What can be accounted for as volunteerism is subject to controversies in the literature. Many authors even question the possibility and necessity of formulating a watertight definition of volunteerism [2,3]. Consequently, the following working definition of volunteerism does not strive for universal validity, but represents the result of an attempt to circumscribe the phenomenon in a very open and inclusive manner while still allowing to distinguish it from closely related types of activities like hobbies or paid work. For these purposes, volunteerism is understood as actions taken up by people based on a voluntary decision, which do not primarily aim at generating economic profit and which are supposed to influence particular as well as vaguely defined social circumstances.

Scholars from different disciplinary backgrounds have studied volunteerism in quite distinct ways and with different research interests. The topic has stirred interest among scholars of such diverse backgrounds as psychology, sociology and political sciences. Accordingly, research questions, methods, theories and concepts applied to the topic of volunteerism vary significantly. For example, while psychologists have mostly studied volunteerism as an individual decision based on particular personality traits, sociologists - while also interested in the question who volunteers and why - have considered volunteerism first and foremost as a social phenomenon and asked what benefits volunteers receive from volunteerism [3]. Political scientists consider volunteerism as a cornerstone for civic society and democratic participation and study the ways in which it establishes particular societal values among citizens.

Although in the framework of the INVOLE-project, the overall aim is the combination of psychological and sociological perspectives in a multi-level theoretical model, this article focuses on the psychological aspect of this work. This perspective strives to explain volunteerism on the level of the individual actor and his or her motivations to volunteer. In the following section, important existing work in this field is reviewed in order to explain how it is built upon and further developed in the INVOLVE-project.

\subsection{Psychological perspectives on motivation to volunteer}

Various works in the field of psychology have attempted to conceptualize volunteerism. Particularly, the works of Clary et al. $[4,5]$ and their model of the Volunteer Functions Inventory (VFI) have received attention for providing a useful theoretical framework to conceptualize motivations of volunteers. In the VFI, volunteerism claims to serve six main functions or motivations, which are values, understanding, enhancement, career, social and protective. Of these, values, understanding and enhancement are claimed to be of greater importance than career, social and protective [5]. Value-driven volunteerism is defined as a way of expressing 
and acting on important values like humanitarianism, understanding-driven volunteerism is defined as a way to learn more about the world or to exercise skills that are often unused and enhancement-driven volunteerism is defined as a way to grow and develop psychologically. Among the lesser important motivations in the VFI, career-driven volunteerism is defined as a way to gain career-related experience, social-driven volunteerism is defined as a way to strengthen the volunteer's social relationships and protective-driven volunteerism is defined as a way to reduce negative feelings, such as guilt, or to address personal problems.

Although the VFI conceptualizes the different motivations as separate entities, the authors stress the multi-motivational nature of volunteering. This means that a person's decision to take on volunteer work is driven by an amalgamation of motivations rather than by a single one. Put differently, the VFI proclaims that volunteers pursue different goals when engaged with one and the same volunteer work.

The VFI provides one way of conceptualizing volunteers' motivations and is a useful starting point to think about why people volunteer in the first place. However, the model can be criticized on various accounts: It is rather eclectic and its theoretical basis is not clearly defined. Most importantly, it ignores existing, more elaborate models about motivation in psychological research. Taking these shortcomings of the VFI into account, the following section introduces a slightly different model that builds upon the main insights of the VFI but integrates them into more general and encompassing psychological theories of motivation.

\subsection{Integrative model for motivation to volunteer}

The work of Dörner [6-8], Bischof [9, 10] and Strohschneider [11, 12] helps to integrate a concept of motivation to volunteer into a general psychological theoretical framework for motivation. Based on these works, the proposed model identifies three main needs that are addressed by voluntary engagement in disaster management. These are the need for affiliation, the need for certainty and the need for control.

The need for affiliation connotes a need of belonging to a form of community. It is satisfied by signals that acknowledge an individual's membership to a group. These signals can involve particularly meaningful gestures and symbols that communicate membership to outsiders as well as insiders, including types of clothing typical for the group or participation in seemingly banal rituals like communal gatherings and group meetings. In the context of disaster management, such signals can be found in uniforms that are typical for a certain group and widely known. Other nonverbal signals of affiliation involve touch and close spatial proximity to each other, which is why for example firefighters have been described as prototypical 'touching cultures' [13]. Coordinated group activities also work as important means to foster a strong bond among members and provide effective affiliation signals to members. Last but not least, affiliation is of course also expressed verbally in everyday encounters between members. Taken together, these different ways of expressing a notion of belonging form an organization's language of affiliation that is important for the smooth collaboration within the group and that works to integrate members in a subtle way.

The second need that drives people to volunteerism is the need for certainty. It is associated with an interest in understanding the world and a desire for predictability and order, fairness and reciprocity. This need is particularly triggered by unexpected, potentially dangerous and disturbing events that are typical for the context of disaster management. It is satisfied by actions (and information resulting from those actions) that re-establish a sense of order in afflicted individuals and render the world calculable again. People who are 
driven by a strong need for certainty can be expected to prefer individual, often short-term, event-related forms of voluntary engagement that do not necessarily involve long-term commitment to a group or organization, in contrast to volunteers who are predominantly driven by a need for affiliation.

Lastly, the need for control denotes a need to actively shape the world, to influence one's surroundings and immediately recognize the effects of one's actions. People with a prominently developed need for control can be expected to feel frustrated by circumstances in which they are not able to recognize the immediate results of their work or in which they have to deal with uncertainty and ambiguity. They strive to 'do things' in a rather straightforward manner and prefer clear task designations and a short delay between action and outcomes. These outcomes are not restricted to the primary agenda of an organization but can also be competences that the volunteer acquires during the course of his or her work. Taken together, if people who are driven by a need for control are able to recognize a particular effect of their engagement, their motivation is sustained.

These basic needs are more or less prominent in every human being, although they are developed to different degrees. They never occur in a singular manner, but people exhibit a mixture of needs that are hierarchized. Similar to the VFI, this model rests upon the claim that it is possible to identify different personal motivations without assuming that these exclude each other.

Furthermore, these needs have to be understood in a bipolar manner in the sense that there can be an abundance of a certain emotional stimulation, which people experience as too much. For example, if a person feels bored by his or her daily work routine, this could be understood as an abundance of certainty that results in a need for uncertainty. Taking up volunteer work can provide that person with a means to achieve just that and satisfy a lust for adventure and excitement. Too much affiliation can trigger a need for de-affiliation and as a result, people might feel an urge to engage in voluntary work on their own or in a smaller group. Likewise, certain work can be experienced as too controlled, which could result in a person losing motivation due to feeling unchallenged in his/her work. In this way, an overstimulation of particular needs can lead to new needs. This makes a careful balancing of volunteers' needs important.

\section{RESEARCH CONTEXT AND METHODS}

Disaster management in Germany lies within the realm of responsibility of the federal and local administrative bodies. Only in the case of war and aggression is the national level responsible, here for the purpose of civil protection and defence [14]. A more detailed comparison of national civil security systems of European states was done in the European research project ANVIL [15].

With respect to German disaster management it is necessary to emphasize that any action carried out in disaster response highly depends upon the engagement of (mostly) unpaid volunteer workers. The greater portion of these volunteers is engaged in disaster management organizations. Overall numbers vary but estimates suggest that approximately 1.5 to 2 million people engage in volunteer work in organizations that are integrated with disaster response. Out of these volunteers, roughly 1.3 million are part of voluntary fire brigades. Approximately 50.000 are part of the only partially nationally funded organization THW (Technisches Hilfswerk), providing technical support in disasters, while the remaining volunteers are organized in various non-profit relief organizations [16]. Throughout recent disaster incidents, e.g. floods, a noteworthy number of volunteers engaged free of organiza- 
tional affiliation. Since these volunteers are more difficult to coordinate outside an organization's structure, relief organizations of disaster response are trying to become more attractive to these volunteers too.

The authors conducted semi-structured and unstructured interviews [17] with volunteers as well as employees of the above-mentioned disaster management organizations and also municipal institutions who work with volunteers. The interviews with volunteers were deliberately designed in an unstructured, open-ended way to allow interviewees to lead the course of the conversation and reflect on their biographical experiences with voluntary engagement. By contrast, the interviews with people who worked with volunteers were semi-structured and followed a stricter protocol with guiding questions.

In total, a number of 40 interviews were conducted with volunteers from different regions of Germany. All of them were active in local-level institutions of various disaster relief organizations, including the Red Cross Society (Deutsches Rotes Kreuz), the Workers' Samaritan Federation (Arbeiter Samariter Bund) and the German Lifeguard Association (Deutsche Lebens-Rettungs-Gesellschaft). Although these institutions work in several regions across Germany, the interview partners were chosen only from urban areas. One reason for this choice of sampling was that disaster sites in densely populated areas potentially affect a high number of people at the same time, thereby creating a need for broad support in disaster management. The interview partners came from the comparably large cities of Berlin and Leipzig, and the smaller town of Jena.

The main aim of these interviews was to collect data on why volunteers engage in the field of disaster management in Germany. Moreover, the study was supposed to generate insights into reasons for volunteers to engage in particular kinds of voluntary work and specific relief organizations. Another interest was in the knowledge of the people working with volunteers with respect to perceived reasons of voluntary engagement and the devised strategies based upon that to attract volunteers.

Interviews were conducted from June 2015 to July 2016, with each interview lasting approximately 90 to 120 minutes. All interviews were digitally recorded, transcribed word by word and analysed using the software tool MAXQDA. Due to the relatively small number of interviews, the analysis dispenses with calculating statistical significances; conclusions were derived qualitatively by in-depth analysis. Since statements of the interviewees are highly valued to infer the motivational basis for their involvement the results presented in this article include a number of verbal quotes. For reasons of confidentiality, no names of interviewees are stated.

\section{FINDINGS}

\subsection{Need for affiliation}

The need for affiliation was at the core of a number of interviewees' statements. A woman in her mid-twenties told that she had started her voluntary work in school when she participated in a project group with a group of four fellow students. She stated that it was the camaraderie within this group that kept her motivated and led to her engagement in the Youth Red Cross (Jugendrotkreuz) after she had completed school. Summarizing her motivation to volunteer, she stated: 'What really keeps me there are the people. I don't really care what it is that I am doing with them. The main thing is that I am in the company of those people'. For her, volunteerism first and foremost was a means to develop a strong bond with other people and 
maintain it through regular meetings with a group of other volunteers and colleagues within the organization. Although she also stated that she was interested in learning about administering first aid, she did not consider this as what kept her motivated to continue her engagement. Instead, she used volunteer work primarily to satisfy her need for affiliation.

This need also resounded in statements that highlighted the importance of regular group meetings. Another woman who worked in the same youth organization of the Red Cross Society in Jena stated: 'Well, you meet every Monday. Really, every Monday we have a team meeting. That creates a very unique feeling of community. Everything is being done in common'. Such regular group meetings are a very common form of satisfying a need for affiliation in volunteers and many other interviewees also mentioned this way of interacting with fellow people being an important factor that kept them motivated to continue their volunteer work over the years.

Other statements also stressed the importance of common meetings and allowed to differentiate the interlocutor's affiliation-centred motivation from other motivations even more clearly. For example, a man in his mid-forties who worked in the DLRG in Berlin stated that what was important for his decision to engage in this kind of voluntary work was the fact that his current engagement was not as strict as other forms of voluntary work in the field of disaster management. He said: 'Well, we don't have such a strict training and because the atmosphere is a bit different from other organizations. After our monthly meeting, when we clean up material and vehicles and prepare things for the next meeting, well, then we also share a beer or two'. In this statement, the interlocutor quite blatantly put the aspect of common leisure upfront and did not refer to more ideological or value-centred motivations as the main reason for him to engage in volunteer work. For him, voluntary work primarily provided a means to meet people he was familiar with and enjoy their company in a context that blurred the boundaries between work and leisure. He also admitted that he was not that interested in trainings or other ways to further expand his practical knowledge. In this way, his statements were in line with the basic assumptions about volunteers who are primarily motivated by a need for affiliation and less so by a need for certainty or control.

\subsection{Need for certainty}

The need for certainty was also prominent in a number of statements. It featured as a main motivation in the statements of a middle-aged woman with a doctoral degree who worked as a voluntary dog trainer in a dog rescue group [German: Rettungshundestaffel] of the local Red Cross Society in Jena. She stated: 'The love for dogs is a part of my motivation and being a part of the team, but the most decisive factor is my enthusiasm for work that contributes to the common good'. When asked if she could imagine other outlets for this motivation, she responded that she also considered the food bank and a recently established refugee camp in Jena as possible places where she could pursue voluntary work. Her statements did not put group cohesion and personal sympathies towards colleagues at the centre, but gravitated towards particular values and ideals to explain her engagement. To her, these values could just as well be realized in other groups and organizations than the ones where she was active already. In other words, she did not engage in voluntary work to satisfy a need for affiliation, but a need for certainty that puts particular emphasis on the creation of a just and fair world. Consequently, she did not link her engagement to a particular group of people - as do people with a more pronounced need for affiliation - but considered the possibility of shifting to other forms of volunteerism in the future. 
Another interviewee who displayed a strong need for certainty was a man who worked for the medical service (Sanitätsdienstliche Einsatzgruppe) of the Red Cross Society in Jena. He had started volunteerism in disaster management while he was in primary school when he had enrolled in the Youth Red Cross and continued his engagement since then in various departments of the Red Cross Society. When asked for the reason why he devoted that much time to voluntary work, he replied: 'I don't want to get any money for my work here. I do it out of some kind of altruism. Ever since I was a child I have some sort of protective instinct. It is simply in my nature to help others'. He identified very passionately with the Red Cross Society's guidelines and ideology and saw it as a way to change the world. He said: 'I know that I alone cannot change the world but I would like to contribute to that with my work'. To achieve this goal, it was important to him to take on responsibility in the organization. As the following quote shows, he would not have been satisfied with what he regarded as menial tasks. He said: 'When you say that you want to help people then it is not done by distributing and buttering bread at a blood donation event'.

This statement shows a clear demarcation between the need for certainty and the need for control. It was important to our interlocutor that he perceived the work he did as relevant and as 'making a difference' in the larger scheme of things. It had to be consistent with his worldview and did not need to foster immediate results.

\subsection{Need for control}

The need for control also provides a strong incentive for many people to engage in volunteer work. One interviewee - the training supervisor of the local department of the Workers' Samaritan Federation - very concisely captured this type of motivation in the expression 'Immediately after you help, you see that you did help'. He described the situation of the floods in Jena in 2013 and claimed that the immediate visibility of results contributed immensely to a heightened availability of volunteers during that catastrophic event. In contrast, he stated that the recent refugee situation with its much less 'controllable' timeframe and unforeseeable development was a less attractive field for possible volunteers, because it did not promise immediate, tangible results. Therefore, one could argue, it was much less attractive for volunteers whose engagement is motivated by a strong need for control and more attractive for those who strive to satisfy a need for certainty.

A 19-year old Law student from Leipzig who had volunteered in various disaster management organizations since his teens and had started volunteering as a paramedic for the Workers' Samaritan Federation half a year ago spoke about the differences between volunteerism and work as a student as follows: 'Well, it is a different kind of work. You have something practical, you see results. With every patient whom I treated, I get a practical result in a rather short amount of time. And that is a different way of interacting with people'. In this statement, the interviewee drew a clear distinction between the rather 'theoretical' work as a student and the 'practical' work as a voluntary paramedic. Translated into the conceptual language of the model for motivations presented here, voluntary work as a paramedic fulfiled the student's need for control much better than did his work at the university. It provided him with tangible results of his work that he felt lacked from his studies. Furthermore, he could experience these results without any delay and in the form of immediate human interaction, another crucial difference to his work as a student. His statement thus resonated a need for control that he could fulfil with his voluntary work. 


\subsection{Further implications}

Certain responses suggest a processual character of motivations for voluntary engagement, as also stated in the VFI [5]. One interviewee from Berlin explained his changing reasons for volunteerism with the words 'You come because of the issue and stay because of the people'. This statement suggests a shift from a need for certainty to a need for affiliation as the dominant motivation to engage in volunteer work. Therefore, it is important to keep in mind that the needs identified in the model outlined in this article can shift over the course of time. Some needs can become more important or even replace others that were dominant at an earlier stage of voluntary engagement. In this sense, voluntary engagement has to be understood not as stable but as a dynamic process.

Furthermore, as stated above, needs do not exclude each other, but are often complementary. For example, the woman quoted above who exhibited a strong need for affiliation also expressed a need for certainty in the same interview. She stated: 'I also come here because I believe in a certain world view and that is simply manifested in the guidelines of the Red Cross Society'. Based on her quotes, it is impossible to decide if her decision to take up volunteerism was primarily rooted in a need for affiliation or a need for certainty or in both in equal measure. Therefore, one has to keep in mind that in most cases of volunteerism a mixture of motivations occurs.

\section{CONCLUSION}

People engage in voluntary work for very different individual reasons. The psychological model presented in this article is intended to further a better understanding of the multitude of volunteers' motivational sources. This model looks at volunteerism in the field of disaster management at the level of the individual actor and reads this phenomenon as a means to address basic psychological needs of human beings. It offers a conceptual tool to categorize these needs and to integrate them into a sophisticated theoretical framework of motivation.

The model proposes three basic human needs that drive volunteers. These are the need for affiliation, the need for certainty and the need for control. These needs do not exist in a singular manner, but are developed to different degrees in every human individual. They also vary according to particular situations and circumstances and can change over time. Traumatic episodes that are typical for contexts of disasters can trigger certain needs for example a need for certainty - and needs that cause an initial decision to take up voluntary work can become replaced by other needs at later stages in the volunteers' life. Taking this dynamic nature of needs into account, the model allows to conceptualize volunteerism and to understand individual motivations to volunteer from a psychological perspective.

These findings have ramifications on how organizations that work in the field of disaster management can address volunteers' needs. In order to improve the integration of volunteers into their structures, organizations should first identify what kind of volunteers they want to attract and design their inter- as well as extra-organizational communication, their trainings and their everyday work routines according to volunteers' needs. This can help both organizations and volunteers working in the field of disaster management to improve their cooperation and set their expectations towards each other in the most appropriate way.

\section{ACKNOWLEDGEMENTS}

This research is funded by the German Ministry for Education and Research (BMBF) contract No. 13N13028 (project: INVOLVE). 


\section{REFERENCES}

[1] Involve, available at www.involve-project.com.

[2] Wilson, J., Volunteering. Annual Review of Sociology, 26, pp. 215-240, 2000. https://doi.org/10.1146/annurev.soc.26.1.215

[3] Hustinx, L., Cnaan, R.A. \& Handy, F., Navigating theories of volunteering: A hybrid map for a complex phenomenon. Journal for the Theory of Social Behavior, 40(4), pp. 410-434, 2010. https://doi.org/10.1111/j.1468-5914.2010.00439.x

[4] Clary, E.G., Snyder, M., Ridge, R.D., Stukas, A.A., Copeland, J. \& Miene, P., Understanding and assessing the motivations of volunteers: a functional approach. Journal of Personality and Social Psychology, 74(6), pp. 1516-1530, 1998. https://doi.org/10.1037//0022-3514.74.6.1516

[5] Clary, E.G. \& Snyder, M., The motivations to volunteer: theoretical and practical considerations. Current Directions in Psychological Science, 8(5), pp. 156-159, 1999. https://doi.org/10.1111/1467-8721.00037

[6] Schaub, H. \& Dörner, D., Eine synthetische Theorie der Motivation. InBericht über den 40. Kongreß der deutschen Gesellschaft für Psychologie in München 1996, ed. H. Mandl, Hogrefe: Göttingen, pp. 855-858, 1997.

[7] Dörner, D., Bauplan für eine Seele, Rowohlt Verlag: Reinbek, 1998.

[8] Dörner, D., Bartl, Ch., Detje, F., Gerdes, G., Halcour, D., Schaub, H. \& Starker, U., Die Mechanik des Seelenwagens. Eine neuronale Theorie der Handlungsregulation, Huber: Bern, 2002.

[9] Bischof, N., Das Rätsel Ödipus. Die biologischen Wurzeln des Urkonfliktes von Intimität und Autonomie, Piper: München, 1985.

[10] Bischof, N., Untersuchungen zur Systemanalyse der sozialen Motivation I: Die Regulation der sozialen Distanz - Von der Feldtheorie zur Systemtheorie. Zeitschrift für Psychologie, 201, pp. 5-43, 1993.

[11] Strohschneider, S., Kompetenzdynamik und Kompetenzregulation beim Planen. In Ja, mach nur einen Plan: Pannen und Fehlschläge - Ursachen, Beispiele, Lösungen, eds S. Strohschneider \& R. von der Weth, 2nd Edn., Huber: Bern, pp. 35-51, 2002.

[12] Strohschneider, S., Ja, mach' nur einen Plan. In Panne - Irrtum - Missgeschick, ed. B. Boothe, Huber: Bern, pp. 127-144, 2003.

[13] Dibiase, R. \& Gunnoe, J., Gender and culture differences in touching behaviour. The Journal of Social Psychology, 144, pp. 49-62, 2004. https://doi.org/10.3200/socp.144.1.49-62

[14] The Crisis Management System in Germany; Federal Ministry of the Interior, Division KM 1 - Crisis Management Coordination Centre, Alt Moabit 140, 10557 Berlin, available at https://www.bmi.bund.de/SharedDocs/Downloads/EN/Broschueren/2012/system_ krisenmanagement_en.pdf?_blob=publicationFile

[15] ANVIL, available at http://anvil-project.net/

[16] Hegemann, H. \& Bossong, R., Country study: Germany, project report. Analysis of Civil Security Systems in Europe [ANVIL]. University of Hamburg: Germany, available at http://anvil-project.net/wp-content/uploads/2013/12/Germany_v1.0.pdf

[17] Lamnek, S., Qualitative Sozialforschung, 5th Edn., Beltz: Weinheim, 2010. 